\title{
CARGAS DE TRABALHO DE MATERIALIDADE EXTERNA NA EQUIPE DE ENFERMAGEM DE HOSPITAL DE ENSINO DO PARANÁ, BRASIL
}

\author{
WORKLOADS OF EXTERNAL MATERIALITY IN THE NURSING \\ TEAM OF A TEACHING HOSPITAL IN PARANÁ, BRAZIL
}

\author{
CARGAS DE TRABAJO DE MATERIALIDAD EXTERNA EN EL \\ EQUIPO DE ENFERMERÍA EN UN HOSPITAL DE ENSEÑANZA \\ DEL ESTADO DE PARANÁ, BRASIL
}

\author{
Iara Aparecida de Oliveira Secco* \\ Maria Lúcia do Carmo Cruz Robazzi ${ }^{* *}$ \\ Francisco Eugênio Alves de SouZA ${ }^{* * *}$ \\ DENISE SAYURI SHIMIZU ${ }^{* * * *}$
}

\begin{abstract}
RESUMO
A investigação objetivou analisar as cargas de trabalho de materialidade externa presentes nos processos de trabalho da equipe de enfermagem de hospital de ensino. Trata-se de estudo realizado sob o referencial teórico do materialismo histórico, cuja análise foi fundamentada na análise de conteúdo proposta por Bardin. Constou de entrevistas semi-estruturadas de sete enfermeiras, gerentes do serviço de enfermagem na Instituição. Para a análise utilizou-se o Programa Informatizado The Ethnograph versão 5.0. Os achados evidenciaram que as cargas biológicas foram as mais relevantes pela exposição e sofrimento que provocam; que as cargas mecânicas têm sido potencializadas pelo envelhecimento dos trabalhadores; que as cargas químicas e físicas parecem ser pouco consideradas pela equipe pouco as conhecer. Ações para aumentar o quantitativo de pessoal e maior acompanhamento desses trabalhadores pelo Setor de Saúde Ocupacional são medidas preventivas fundamentais para a melhora das condições de saúde e trabalho da população estudada.
\end{abstract}

Palabras chave: Carga de trabalho, enfermagem, hospitais de ensino, saúde do trabalhador.

\begin{abstract}
The purpose of this study was to analyze workloads of external materiality present in the work processes of the nursing staff of a teaching hospital. Historical materialism was the theoretical framework, whose analysis was based on content analysis proposed by Bardin. Semi-structured interviews were held with the participation of seven nurses, who were nursing service managers in the institution. The Ethnograph version 5.0. software was used for analysis. Findings evidenced that the biological loads were the most relevant ones, due to the exposure and suffering they provoke; that the potential of the mechanical loads has increased due to the workers' aging; that chemical and physical loads are hardly taken into account because of the team's lack of knowledge. Actions

\footnotetext{
*Enfermeira. Gerência de Pesquisa do Hospital Universitário da Universidade Estadual de Londrina. Brasil. Email: iarasecco@sercomtel.com.br

${ }^{*}$ Enfermeira. Professor titular da Escola de Enfermagem de Ribeirão Preto da Universidade de São Paulo. Brasil. Email: avrmlccr@glete.eerp.usp.br

${ }^{* * *}$ Médico. Docente da Universidade Estadual de Londrina. Brasil. Email: kiko@uel.br

${ }^{* * * *}$ Enfermeira do Trabalho da Prefeitura Municipal de Paranaguá. Brasil. Email: deniseshimizu@bs2.com.br
} 
to increase the number of staff members and greater follow-up of these workers by the Occupational Health Sector are fundamental prevention measures to improve this population's health and work conditions.

Key words: Workload, nursing, hospitals, teaching, occupational health.

\section{RESUMEN}

La finalidad de la investigación fue analizar las cargas de trabajo de materialidad externa presentes en los procesos de trabajo del equipo de enfermería de un hospital de enseñanza. Se trata de un estudio realizado según el marco teórico del materialismo histórico, cuyo análisis se basó en el análisis de contenido propuesta por Bardin. Abarcó entrevistas semiestructuradas de siete enfermeras, gerentes del servicio de enfermería en la Institución. Para el análisis fue utilizado el Programa Informatizado The Ethnograph versión 5.0. Los hallazgos evidenciaron que las cargas biológicas fueron las más relevantes, debido a la exposición y el sufrimiento que provocan; que las cargas mecánicas han sido potencializadas por el envejecimiento de los trabajadores; que las cargas químicas y físicas parecen ser poco consideradas porque el equipo las conoce poco. Acciones para aumentar el cuantitativo de personal y mayor acompañamiento de esos trabajadores por el Sector de Salud Ocupacional son medidas preventivas fundamentales para mejorar las condiciones de salud y trabajo de la población estudiada.

Palabras clave: Carga de trabajo, enfermería, hospitales escuela, salud laboral.

Fecha recepción: 17/11/09 Fecha aceptación: 22/08/11

\section{INTRODUÇÃO}

Hospitais são estabelecimentos de assistência à saúde nos quais os trabalhadores de enfermagem atuam com o objetivo de atender os usuários dos serviços no enfoque do modelo clínico individual, utilizando instrumentos específicos para essa prática e desenvolvendo um processo de trabalho que leva em conta o planejamento das atividades, sua organização, realização, acompanhamento e avaliação da assistência prestada na área.

Conceitualmente, trabalho refere-se ao empreendimento das forças e potencialidades físicas e psíquicas que o homem utiliza para satisfazer suas necessidades ou para atingir seus objetivos; o trabalho interfere nas condições e qualidade de vida do homem e, portanto, na sua saúde. O estudo da relação entre saúde e trabalho, com base no referencial explicativo da Teoria da Determinação Social do Processo Saúde-Doença, apresenta-se como um fundamento do campo da Saúde do Trabalhador $(1,2)$.
A forma de organização da sociedade no sistema capitalista apresenta os seguintes componentes: processo de valorização, que se concretiza a partir do desenvolvimento do processo de trabalho e da produção de bens e serviços que tem valor para a sociedade; do processo de trabalho, a partir da organização e divisão da atividade laboral visando a transformação da natureza para a obtenção de um objeto útil; das cargas de trabalho, que dizem respeito às relações que ocorrem entre a exposição do trabalhador requerida pela atividade laboral e as conseqüências para a sua saúde, que se materializam no desgaste operário, tanto físico quanto mental $(1,2)$.

Nessa perspectiva, reproduzindo o processo de produção capitalista, o processo de trabalho da enfermagem hospitalar, por meio da equipe constituída por enfermeiros, técnicos e auxiliares de enfermagem, tem como finalidade maior prover assistência ao usuário dos serviços, sendo a tônica o cuidado, a assistência integral, individualizada e humanizada. Instrumentos de trabalho envolvem o conhecimento técnico e científico da área, 
o conhecimento gerencial e institucional, as instalações físicas, os materiais e equipamentos utilizados, os diagnósticos de enfermagem e médico, a prescrição de enfermagem, a maneira como o serviço é dividido e organizado entre os prestadores da assistência. Ademais, é notória a participação do pessoal de enfermagem nos processos administrativos das referidas instituições, nas atividades de ensino e pesquisa, especialmente naquelas com características de hospitais de ensino.

Trabalhadores de enfermagem têm de suportar o desgaste físico e psíquico da lida com a dor e o sofrimento, dos imprevistos das salas de emergência e cirúrgicas, com a necessidade de adaptação a novas tecnologias e alteração na produção dos serviços, do cotidiano que necessita compatibilizar a profissão pouco reconhecida e mal remunerada com a própria manutenção e a de seus dependentes; esses fatores traduzem-se em cargas de trabalho que revertem em desgaste para o trabalhador, cujo enfrentamento requer postura de resistência, num processo adaptativo, para superar as dificuldades apresentadas no cotidiano.

Cargas de trabalho constituem-se nos elementos do processo de trabalho que interagem dinamicamente entre si e com o corpo do trabalhador, desencadeando alterações no seu processo saúde-doença e manifestando-se em desgastes físicos e psíquicos. São classificadas em cargas de materialidade externa (físicas, químicas, biológicas e mecânicas), que podem ser identificadas independentemente do corpo do trabalhador, podem ser detectadas e até medidos sem envolvê-lo, constituindo-se no objeto do presente estudo; e as de materialidade interna (fisiológicas e psíquicas), cuja característica é poderem ser pensadas ou identificadas apenas através do corpo do trabalhador, serem próprias dos processos intracorporais, adquirindo materialidade através da corporeidade humana, necessariamente $(1,2)$.

As cargas biológicas estão presentes na atividade dos trabalhadores de enfermagem hospitalar pela exposição às bactérias, vírus, fungos, parasitas, entre outros, que podem desencadear doenças graves como a síndrome da imunodeficiência adquirida (AIDS), as hepatites B e C; as cargas físicas estão expressas no ruído, nas vibrações e/ou radiações emanadas da maquinaria, nos extremos de temperaturas do ambiente, na umidade, na ventilação e iluminação inadequadas; as cargas químicas efetivam-se nas tarefas de preparo e administração de medicamentos, no manuseio de produtos químicos, no contato com gases e vapores; as mecânicas são vivenciadas durante a movimentação de pacientes, no transporte de materiais e aparelhos, na utilização de mobiliário inadequados, nas condições de instalação e manutenção de equipamentos; as fisiológicas resultam do trabalho em turnos, da dupla ou tripla jornada, da realização de horas-extras, da sobrecarga de atividades pela exigência da produtividade, dos esforços físicos e posições assumidas durante os atendimentos e, por fim, as psíquicas decorrem do estresse diário, do convívio com a morte, da intensificação das tarefas, das relações profissionais com a chefia, da organização e divisão do trabalho, desencadeando fadiga, alterações de humor, distúrbios psíquicos, entre outros (3).

As cargas de trabalho presente nos processos de trabalho não somente se somam, mas se potencializam e dão consistência ao processo de produção, caracterizando-o de forma específica, podendo incorrer, inclusive na ocorrência de acidentes e/ou doenças relacionadas ao trabalho (2). O acidente de trabalho (AT) é entendido como aquele que ocorre no exercício do trabalho e que traz como conseqüência lesão corporal ou perturbação funcional, com perda ou redução da capacidade laboral, de forma permanente ou temporária, ou até mesmo a morte. É denominado acidente de trabalho típico (ATT) aquele ocorrido no ambiente laboral, como doença profissional aquela produzida ou desencadeada pelo exercício do trabalho inerente à atividade e, doença do trabalho é 
aquela adquirida ou desencadeada por condições especiais em que a atividade laboral é realizada e que com ela se relaciona (4).

Ponto a ser destacado é o caráter histórico do processo saúde-doença, o conhecimento da articulação da relação trabalho-saúde, para poder compreender como esse processo se articula e expressa.

$\mathrm{O}$ presente estudo se justifica pelo fato do Hospital de Ensino (HE) figurar entre as principais instituições assistenciais, de ensino e pesquisa do interior do Estado do Paraná, Brasil. Conhecer as cargas de trabalho dos 648 trabalhadores de enfermagem do quadro funcional do Hospital possibilita a maior eficiência na gestão das pessoas e dos processos de trabalho desenvolvidos, a preservação e a promoção da saúde da equipe, fatores esses que repercutem, irrefutavelmente, na qualidade dos serviços prestados.

A investigação ora apresentada ateve-se a divulgar as cargas de materialidade externa de enfermagem por essas serem visíveis e dizerem respeito, necessariamente, ao processo de trabalho desenvolvido na Instituição, à forma como ele é organizado e desenvolvido. Essas cargas, por dizerem respeito aos elementos externos ao corpo do trabalhador, independem das particularidades dos complexos processos intracorporais, característicos das cargas de materialidade interna e que requerem análise particularizada.

Objetivo: Analisar as cargas de trabalho de materialidade externa (biológicas, físicas, químicas e mecânicas) presentes no processo de trabalho da equipe de enfermagem de hospital de ensino do Estado do Paraná (Brasil).

\section{MATERIAL E MÉTODOS}

Trata-se de pesquisa com abordagem qualitativa, sob o referencial teórico do materialismo histórico desenvolvido por Laurell e
Noriega, cujo direcionamento investigativo é especifico da área da Saúde do Trabalhador. O materialismo histórico investiga a relação existente entre trabalho, saúde e doença nos grupos sociais, sendo o processo de trabalho um de seus determinantes. Esta proposta fundamenta-se no reconhecimento da historicidade do caráter social da saúde-doença e na compreensão do trabalho como um complexo processo social e técnico, que traz o desgaste do trabalhador como conseqüência $(1,2)$.

O Hospital Universitário da Universidade Estadual de Londrina (HE) é hospital público, geral, de grande porte, cujas atividades tiveram inicio no ano de 1970. É considerado o terceiro maior hospital escola do sul do Brasil, com todos os seus 333 leitos disponibilizados ao Sistema Único de Saúde (SUS), constituindo-se em referência para usuários do município onde está instalado e região para todas as especialidades médicas. Contava com 1.742 servidores, dos quais $37,2 \%$ (648) eram da equipe de enfermagem, em 2005, período da coleta de dados (5).

Foram sete as informantes-chave da presente investigação, realizada por meio de entrevistas semi-estruturadas. Participaram a diretora de enfermagem, a enfermeira da comissão de controle de infecção hospitalar e as enfermeiras-chefe das cinco divisões de enfermagem que apresentaram maiores indicadores risco de ATTs constantes em Relatório Institucional, a saber: Pronto Socorro (PS), Centro Cirúrgico (CC), Unidade de Terapia Intensiva Adulto (UTI), Divisão de Internação e Divisão Materno-Infatil. Seus depoimentos foram identificados na presente investigação com a abreviatura ENF (de enfermeiro), acompanhadas de seqüencial numérico de um a sete, correspondendo a cada uma das sete participantes, garantindo o anonimato e facilitando a leitura.

Os critérios de inclusão deram-se pelo fato dessas profissionais chefiarem e, para desenvolverem tal atividade, devem, necessariamente, conhecer os processos de trabalho 
da equipe nos setores sob sua coordenação ou campo de atuação, para poder gerenciar o serviço.

Nas entrevistas foi perguntado às enfermeiras quais as cargas de trabalho presentes nos processos de trabalho da equipe de enfermagem do $\mathrm{HE}$ e que possibilitavam a ocorrência dos acidentes e desgastes físicos e emocionais, com repercussões no processo saúde-doença dos trabalhadores.

Para a análise dos dados relativos às questões norteadoras realizadas nas entrevistas foi utilizada a técnica de análise de conteúdo, definida como um conjunto de técnicas de análise da comunicação, que objetiva obter indicadores que possibilitem o conhecimento de aspectos relativos às condições de produção e da recepção dessas mensagens apresentadas $(6,7)$.

Para efetuar a análise de conteúdo é necessário proceder a classificação, ordenação, quantificação e interpretação das respostas verbais e outras manifestações simbólicas dos sujeitos participantes da pesquisa $(6,7)$.

Ainda, faz-se necessário superar o conteúdo manifestado na mensagem e inferir, para alcançar uma interpretação mais aprofundada $(6,7)$.

A análise e interpretação dos resultados foram realizadas, primeiramente, pela leitura exaustiva do conteúdo das entrevistas transcritas, objetivando a sua compreensão. Para operacionalizar tanto a ordenação e separação das unidades de sentido das categorias analíticas, quanto para realizar o posterior reagrupamento dos dados em blocos temáticos, foi utilizado o Programa Informatizado The Ethnograph versão 5.0, que é específico para pesquisa qualitativa.

Identificadas as categorias analíticas "o processo de trabalho da enfermagem hospitalar" e "as cargas de trabalho de enfermagem", foi estabelecido o esforço interpretativo das idéias apresentadas pelos informantes, a correlação desse conteúdo com o referencial teórico, com vistas à elaboração da síntese desse conhecimento.
Destaca-se que a investigação considerou, além dos depoimentos apresentados pelas informantes-chave, documentos institucionais e a vivência dos pesquisadores na atuação assistencial no Hospital estudado. Também, que o estudo foi autorizado pelo Comitê de Ética em Pesquisa do próprio HE, com parecer favorável No 26, de 03/04/2003, tendo sido desenvolvido conforme as diretrizes determinadas pela Resolução No 196/96 do Conselho Nacional de Saúde (8).

\section{RESULTADOS}

Conforme já exposto previamente, o HE estudado tem a característica de ser público, totalmente vinculado ao SUS e de Ensino, constituindo-se em órgão suplementar de universidade pública estadual.

Os 648 trabalhadores de enfermagem do HE, no período estudado, apresentavam a característica de ser majoritariamente feminino, totalizando $78,7 \%$ (510) do quadro; ainda, 43,1\% (279) do pessoal estava na faixa etária entre 40 e 50 anos e 26,1\% (169) já se apresentavam com mais de 50 anos. A rotatividade apresentada era baixa, possivelmente em razão da estabilidade no emprego que o serviço público confere, assim como o fato do salário estar compatível com a realidade regional; conseqüentemente, a tendência do envelhecimento da população é presumível, assim como as repercussões dele esperadas, pela emergência de problemas de saúde decorrente dos desgastes naturais que a vida e o trabalho apresentam nos componentes da equipe (5).

É notório o maior contingente de trabalhadores do nível médio no Hospital. Os enfermeiros, em menor número $(14,8 \%=96)$, ficam encarregados das tarefas gerenciais, havendo grupos hierarquicamente definidos, sendo os enfermeiros de campo subordinados aos chefes de Seção (responsáveis pelos diversos setores de trabalho), seguindo-se na 
escala hierárquica os chefes de Divisão e ao diretor de Enfermagem, sendo estes últimos sujeitos da pesquisa $(5,9)$.

Quanto ao tempo de trabalho na instituição, o fato de 68,8\% (446) do pessoal ter mais de 10 anos de atividade no HU faz com que se possa aventar a existência de um grupo estável, conhecedor da política institucional, da sua trajetória histórica e social, cuja cultura organizacional possibilita o desenvolvimento de políticas de trabalho bem definidas. Sendo assim, mesmo havendo alguma rotatividade de pessoal, há grupos bem definidos na estrutura da organização que, ao mesmo tempo em que lhe dá segurança, podem contribuir para a manutenção de um estilo tradicional no desenvolvimento do trabalho (5).

No que se refere ao duplo emprego formal, sem contar as atividades domésticas inerentes à situação da mulher, foi possível constatar que 20,7\% (134) dos trabalhadores possuíam esse duplo emprego, o que significa pelo menos o quantitativo de atuação de 72 horas de trabalho semanais, muitas vezes em regime de plantões noturnos seguidos. Digno de nota é que este quantitativo refere-se apenas ao trabalho formal, não estando contados os do informal e nem as atividades domésticas que tanto consomem o trabalho e a atenção das mulheres, principalmente (5).

Os indicadores de acidentes de trabalho mostraram os níveis de 89,0\% (349) típicos, com coeficiente de risco médio anula de 9,2 eventos para cada 100 trabalhadores (9).

$\mathrm{O}$ regime jurídico que rege as relações de trabalho dos servidores do HE é o dos funcionários civis do Poder Executivo do Estado do Paraná, denominado Estatuto do Servidor Público (10). Essa legislação sofreu alterações ao longo dos anos, culminando com a Lei Estadual No 15.050, de 12/04/2006, que manteve, entre deveres e benefícios, a manutenção da estabilidade funcional para servidores com mais de três anos de atividade na instituição, a garantia da assistência à saúde em casos de doenças relacionadas ao traba- lho, acidentes e outros (11).

Nesse contexto institucional os trabalhadores de enfermagem do HE desenvolvem a sua atividade laboral segundo os princípios da administração científica de Taylor e Ford no modelo clássico, em que há a divisão do trabalho, na perspectiva de que, hegemonicamente, o grupo dos enfermeiros tem a responsabilidade da programação, da gerência dos serviços, cabendo aos trabalhadores de nível médio (auxiliares e técnicos de enfermagem) a da execução de grande parte das tarefas. Também, utilizam a teoria da $\mathrm{Bu}$ rocracia de Weber, com a normatização de procedimentos, estabelecimento de rotinas e organogramas, tendo destaque a competência profissional e técnica. A teoria clássica de Fayol, por sua vez, mostra-se com a divisão do trabalho com as especialidades, com a disciplina rígida e a adoção das fases do modelo tradicional da administração, desde o planejamento, organização, direção, controle e avaliação (12).

O processo de trabalho de enfermagem desenvolvido no HE sobrepõe as cargas de trabalho ao corpo dos trabalhadores e, a busca de compreender essa realidade $(6,7)$, especificamente as cargas de materialidade externa, mostrou os achados a seguir apresentados, por meio dos depoimentos das enfermeiras-chefes.

As cargas biológicas foram classificadas pelas entrevistadas como fator principal de apreensão e sofrimento, tanto para elas como para a equipe. $\mathrm{O}$ risco de ser acometido por doenças infecciosas graves, sobretudo a AIDS, traz expressiva inquietação aos que atuam na assistência direta aos pacientes, bem como para aqueles que manipulam materiais contaminados com fluidos corporais, especialmente sangue.

Em relação a esta problemática foram apresentadas nas entrevistas as dificuldades vivenciadas pela equipe para atender pacientes soropositivas para o HIV ou doentes de AIDS, em razão do conflito entre prestar assistência e manter uma atitude compatível 
com a própria proteção. Por outro lado, no que diz respeito às medidas de proteção individual, que muitas vezes não são seguidas durante as atividades, algumas informantes-chave supuseram que esse comportamento se deve ao estigma religioso e à cultura do pessoal de enfermagem, advinda da crença na proteção divinal, que supera qualquer outro tipo de ação preventiva, assim como à negação da penosidade que a atividade confere (Enf. 3-4).

Uma das informantes mostrou indignação pela resistência do pessoal ao uso de luvas durante procedimentos em que ele é indicado (Enf. 1). Outra participante revelou que raramente nota a utilização deste equipamento protetor durante o procedimento de punção venosa; considerou que a resistência deve-se à maior dificuldade prática pela diminuição da sensibilidade da mão do profissional no toque, no momento da realização da tarefa (Enf. 3). Outro ponto levantado é que há maior adesão ao uso das luvas no referido procedimento quando o paciente é, reconhecidamente, portador de alguma doença veiculada pelo sangue ou está internado no Setor de Moléstias Infecciosas, em razão de uma cobrança mais intensa por parte da chefia daquele setor (Enf. 6).

Sobre o uso de luvas para punção venosa eu tenho que dizer que é difícil puncionar com elas e creio que é por isso que há tanta resistência por parte do pessoal de enfermagem. Raramente vejo o funcionário usando... É diferente quando o paciente é sabidamente soropositivo para o HIV, situação em que todos se protegem... Eu acho que é preciso valorizar quando o trabalhador diz: eu não consigo pegar uma veia difícil com luva, ela enrosca no garrote, eu acabo perdendo a punção...(Enf. 3).

Uma delas destacou que não entende a resistência da equipe ao uso das técnicas adequadas de biossegurança durante a atividade laboral, talvez pelo dinâmico ritmo das atividades diárias, que exigem efetividade nos serviços. Contudo, outra entrevistada fez o seguinte questionamento a respeito da prática da lavagem de mãos nos setores:

O que acontece, por quê tamanha resistência? É impossível que a pessoa deixe de lavar a mão em sã consciência... Eu acho que isso é uma defesa, é desconsiderar o risco, fazer de conta que ele não existe para se fortalecer e continuar (Enf. 4).

O número crescente de pacientes portadores de infecções por bactérias multirresistentes foi apresentado como fator de preocupação também para outras entrevistadas, assim como a permanência de pacientes com tuberculose, especialmente no PS e UTI, aguardando a confirmação diagnóstica, antes de serem encaminhados para o Setor de Tisiologia.

Os depoimentos revelaram a existência desses muitos entraves presentes no processo de trabalho, influenciados pela organização institucional, pela forma como se entrelaçam as questões educativas, políticas e estruturais do HE, fatores que terminam por comprometer a prevenção dos ATTs envolvendo a exposição dos trabalhadores a materiais biológicos, trazendo à tona grande expectativa e inquietação para todos (Enf. 1;2;4;6).

Cargas físicas decorrentes das condições do ambiente e da crescente introdução de novas tecnologias nos hospitais têm se mostrado como fonte de cargas de trabalho para a equipe de enfermagem. É preciso considerar que a Instituição em estudo, por não ter sido planejada para ser um hospital geral, teve seus espaços ampliados paulatinamente, de maneira improvisada, de acordo com as necessidades que o serviço de saúde local passou a demandar ao longo dos anos. Essas áreas, muitas vezes, oferecem pouca ventilação, são exíguas, possuem iluminação inadequada, o que traz repercussões nos processos de trabalho, além de desconforto para usuários dos serviços, de suas famílias e de toda a equipe de saúde. 
A existência de unidades de trabalho totalmente fechados tais como as UTIs, CC, espaços nem sempre climatizados, com pequenas janelas próximas ao teto, faz com que os trabalhadores de enfermagem tenham acréscimo de desconforto durante a atividade laboral.

Um dos sujeitos entrevistados observou que medidas têm sido tomadas na busca de alterar esse quadro. Destacou que foram instaladas grandes janelas na UTI Adulto, o que tornou o espaço mais confortável, reduzindo o desconforto do recinto fechado.

Depois da instalação de janelas na UTI, passamos a saber quando era dia e quando era noite, se chove ou faz sol... Passamos a perceber uma maior satisfação na fisionomia das pessoas da equipe, todos passaram a se sentir melhor. $O$ próprio paciente também sentiu melhora; nós percebemos que diminuiu o número de idosos com crise de agitação, a localização do doente no tempo e espaço contribui para a sua recuperação (Enf. 2).

Sobre as condições do ambiente de trabalho, a enfermeira chefe do PS relatou a existência de um fluxo intenso de pessoas no setor, pessoas de todas as idades e classes sociais, fumantes em áreas com presença de rede de oxigênio, presidiários cujo atendimento exige organização especial do local, entre outros. Asseverou que a planta física é inadequada, o que dificulta sobremaneira o trabalho, especialmente o atendimento das emergências (Enf. 7).

Constatou-se, também, que o pessoal do CC fica particularmente exposto, cotidianamente, às cargas físicas e aos acidentes graves de cuja ocorrência elas são causas expressivas. Entre as ilustrações utilizadas por um dos sujeitos (Enf. 2) esteve o episódio de um desfibrilador cardíaco que se incendiou, o caso da água da chuva que entrou pela tubulação elétrica, as situações de choques sofridos durante o manuseio de bisturi elétrico, entre outras. Também lembrou que a existência de número excessivo de aparelhos ligados à eletricidade e os numerosos fios no chão, os quais provocam quedas em momentos em que há necessidade de maior agilidade e rapidez.

As entrevistadas relataram que há muito barulho no HE; uma delas lembrou a movimentação da cerca de 3.200 pessoas por dia, entre pacientes, alunos, visitantes, funcionários, docentes, fornecedores, repercutindo inevitavelmente no aumento do ruído (Enf. 4).

Outra participante asseverou que a UTI Adulto, de maneira especial, sofre a problemática do ruído durante a atividade laboral, emanado das pessoas presentes, da aparelhagem em funcionamento, dos alarmes sonoros, do som dos respiradores em uso, das bombas infusoras, do alarme dos oxímetros de pulso, do sistema de som, das enceradeiras utilizadas na limpeza dos pisos, das chamadas veiculadas pelos alto-falantes, todas situações que trazem estresse e cansaço à equipe e comprometem a concentração do pessoal durante a execução das tarefas (Enf. 6).

De fato, esses ruídos e movimentação podem fazer com que o paciente que está mais lúcido e orientado, fique atento, preocupado e assustado, tal como apresentado a seguir:

Que barulhão é aquele que o pessoal faz atrás da cortina, quando um paciente passa mal? (Enf. 6) foi uma das falas de um dos sujeitos deste estudo, reproduzindo o testemunho do enfermo que viu e ouviu situação inusitada do atendimento de uma parada cardiorrespiratória em uma enfermaria com vários leitos.

No Centro de Material (CM), que apresenta pouca ventilação, a temperatura das autoclaves gera calor e umidade. Com o objetivo de melhorar o conforto do pessoal foram instaladas "cortinas de ar" para tentar melhorar a circulação, mas, o ruído desencadeado foi insuportável e segundo uma das participantes da pesquisa, os trabalhadores preferiram sofrer com o calor a ter que suportar o barulho provocado por esse equipa- 
mento (Enf. 2).

Foi possível notar nos depoimentos a necessidade de manter a perspectiva, a esperança de que as condições do ambiente um dia serão favoráveis.

Quando pudermos ter enfermarias mais arrumadas, de dois leitos, climatizadas, um ambiente mais agradável, isso tudo vai ajudar a melhorar o clima, as pessoas vão trabalhar com mais prazer, vão aderir mais às normas de proteção individual. Vai faltar a questão salarial, que não tem como nós interferirmos... (Enf. 3).

Cargas químicas presentes na atividade laboral do pessoal de enfermagem, pelo manuseio de substâncias de variadas naturezas, desde quimioterápicos, antibióticos, álcoois, desincrostantes, entre outros, fazem parte da rotina diária. Como conseqüência há os ATTs, as alergias, as rinites e outros agravos, muitas vezes imperceptíveis no curto prazo.

Constatou-se a preocupação dos sujeitos com o acesso facilitado a produtos como entorpecentes, álcool, éter, substâncias passíveis de serem utilizadas como drogas ou narcóticos. Isso diz respeito tanto aos trabalhadores do HE de todas as áreas, quanto aos pacientes que, por serem submetidos a internações repetidas, terminam por conhecer os fluxos de pessoal e material, bem como fragilidades de controle de acessos da Instituição (Enf. $4 ; 5 ; 6 ; 7)$.

Entretanto as cargas químicas parecem não ser de grande preocupação por parte do pessoal de enfermagem, incorporadas que estão em seu cotidiano laboral. Parecem ser menos visíveis à equipe, com exceção das substâncias que provocam queimaduras, lesões mais graves ou aparentes, o que pode refletir a falta de conhecimento a respeito do assunto. Possivelmente, outros problemas podem estar ocorrendo, merecendo devida análise.

Cargas mecânicas estão especialmente presentes no processo de trabalho de enfermagem do HE, repercutindo de maneira evi- dente no corpo do trabalhador, ainda mais considerando o aumento gradativo da média da idade do pessoal, uma vez que $43,1 \%$ (279) figuravam na faixa etária entre 41 e 50 anos e $26,1 \%$ (169) com mais de 50 anos.

Segundo os sujeitos, o atendimento aos pacientes, especialmente em situação de urgência, exige esforço físico com conseqüente desgaste, assim como a atividade de transportá-los (Enf. 6;7). Os agravos à saúde decorrem das posições anti-ergonômicas dos profissionais durante o trabalho, da necessidade de autoproteção contra a agressão de usuários, do manuseio de equipamentos pesados, da utilização de cadeiras de rodas com defeito nos rodízios, das manobras necessárias para empurrar macas ocupadas por corredores repletos de pacientes e pessoas que circulam pelo Hospital. Um depoimento ilustra essas dificuldades:

No PS, freqüentemente, nós temos pacientes obesos que chegam passando mal e que exigem esforço extremo do pessoal de enfermagem para realizar o transporte. Há muitas emergências com essas características e isto traz sobrecarga, sem contar os deficientes físicos, que também precisam de cuidados especiais (Enf. 7).

Sobre o assunto, outra participante lembrou que, para movimentar pacientes com peso excessivo, a exemplo dos que realizam gastroplastia, há colaboração de todo o grupo e o esforço parece ser menor quando comparado à força física exigida para movimentar pacientes com peso mediano; nessas ocasiões o trabalhador acaba assumindo sozinho a mobilização, sendo obrigado a empregar mais energia, visto que os colegas estão sempre atarefados (Enf. 6).

Esclareceu que o pessoal da UTI tem nas cargas mecânicas a maior fonte de problemas de saúde, em razão do número de pacientes com dependência física. Destacou que um funcionário teve o plexo braquial rompido durante o trabalho, outro teve lesão na coluna lombar, outro foi abalroado por um pa- 
ciente com agitação psicomotora, cujas conseqüências foram os óculos quebrados, lesão na face e afastamento do trabalho (Enf. 6).

Uma informante referiu que, entre as providências tomadas para minimizar a sobrecarga mecânica da equipe da UTI, foi a adoção de um equipamento tipo elevador, que deveria ser utilizado para levantar o paciente. Contudo, o mesmo não foi aprovado pelo grupo, com a alegação de que o seu manuseio dificultava ainda mais o andamento do trabalho (Enf. 4).

Os sujeitos, embora conscientes das expressivas cargas de trabalho de enfermagem no HE, sustentaram nos depoimentos a postura de resistência, de solidez, possivelmente na busca de suportar o peso das suas responsabilidades e manter a marca da esperança em melhores dias para os trabalhadores e para os pacientes do hospital.

\section{DISCUSSÃO E COMENTAR}

As cargas de trabalho de materialidade externa presentes no processo de trabalho da enfermagem de HE constituíram-se no objeto do presente estudo, que foi desenvolvido na perspectiva de compreender esse processo, buscar o seu entendimento $(6,7)$.

É preciso considerar que o trabalho de enfermagem estudado se dá no contexto histórico e social de hospital público, organizado segundo o modelo clinico, individual, biologista, desenvolvido por tarefas, na maioria dos setores, que é inerente ao processo de produção capitalista. Junto a essa imperiosa exigência de atenção à saúde, há as demandas da administração geral da Instituição, as do controle social crescente do SUS e as da academia, que requerem condições favoráveis para o desenvolvimento do ensino e da pesquisa.

O HE, desde sua implantação em 1971, tem desempenhado papel estratégico no âmbito do sistema de saúde regional do Estado do Paraná, tendo como finalidade precípua o desenvolvimento das ações de formação de recursos humanos na área da saúde, dado que se trata de órgão suplementar de Universidade Pública, a educação continuada, a pesquisa e desenvolvimento tecnológico, a cooperação técnica e científica com a rede de serviços de saúde, a assistência à saúde da população, entre outros.

Essa expressão do hospital na comunidade origina um grande reconhecimento social, que se traduz em sentimento de orgulho para os seus trabalhadores, ao mesmo tempo em que impõe o censo de responsabilidade por atender a expectativa da sociedade, especialmente da população com condições sócio-econômicas menos favoráveis, que mais se utiliza dos serviços oferecidos.

Entretanto, reconhecer os entraves existentes no gerenciamento da assistência de enfermagem em hospitais públicos, de ensino, é um especial desafio, pois se faz necessário compatibilizar a necessidade da produção de serviços, apoiada na racionalidade técnica dos procedimentos, ao seu arcabouço administrativo, com poucos mecanismos de controle e maior morosidade nos empreendimentos. A administração pública, além de atender a uma série de procedimentos legais, o que é absolutamente adequado e necessário, também faz concessões ao quadro funcional, como licenças-prêmio (afastamento remunerado no trabalho por 90 dias a cada cinco anos de atuação, liberação de dia de trabalho quando está interposto entre o feriado e o final-de-semana e outros), sem prever e dispor de suporte estrutural capaz de suprir a força de trabalho exaurida por esses benefícios.

A gerência do serviço de enfermagem é atribuída ao enfermeiro, sobre o qual pesa a responsabilidade do planejamento, coordenação e controle dos serviços prestados na área, bem como a assistência direta a pacientes graves. A complexidade da tarefa da gestão de pessoas no serviço público, que oferece benefícios sem fornecer o respaldo 
necessário para tal, foi explicitada nas falas dos participantes do estudo; observou-se, por vezes, que essa responsabilidade pesa sobre essas enfermeiras-chefes, que igualmente pertencem ao referido grupo funcional, que gozam de seus benefícios e compartilham suas agruras.

As repercussões das cargas de trabalho presentes no processo de trabalho e no processo saúde-doença do trabalhador de enfermagem hospitalar estão entre os maiores problemas vivenciados pela equipe e pelas instituições, com destaque para aqueles decorrentes dos ATTs, considerando-se a maneira abrupta e visível com que ocorrem na sua vida $(3,5,9,13-15)$.

$O$ processo de trabalho de enfermagem do HE apresenta-se dividido entre o manual, realizado majoritariamente pelo pessoal de nível médio, e o gerencial, realizado pelos enfermeiros, expressando a divisão social do trabalho que, conseqüentemente, impõem diferentes padrões de desgaste laboral.

A notória presença de cargas biológicas, físicas, químicas e mecânicas, foco dessa pesquisa, assim como as fisiológicas e psíquicas, no processo laboral desses trabalhadores os predispõem à ocorrência de ATTs e doenças relacionadas ao trabalho, o que demanda mais estudos e atitudes concretas para o enfrentamento da referida problemática (13, 14).

Nessa investigação as cargas biológicas foram as que mostraram maior relevância no ponto de vista dos sujeitos entrevistados. Tal situação corrobora outros resultados que igualmente, consideraram também o sofrimento que esses eventos provocam no trabalhador $(5,9,13,16,17,18)$.

Efetivamente as cargas mecânicas têm sido potencializadas pelo envelhecimento de expressivo contingente de pessoal, inclusive impossibilitando parte do grupo de continuar atuando na atividade laboral de forma plena, o que torna necessária a instauração de processos de readequação e/ou readaptação funcional. Contudo, essa situação acarre- ta outros problemas para a equipe, uma vez que a realização das tarefas continua sendo exigida, sobrecarregando os demais que permanecem em atividade e que passam a ser as próximas vitimas potencias.

Cargas físicas e químicas pareceram ser pouco valorizadas pelo grupo, possivelmente em razão do menor conhecimento sobre elas e dos problemas que podem acarretar, o que se observou também em outras investigações centradas nessas áreas específicas $(19,20)$.

É fato que as cargas do processo de trabalho de enfermagem podem provocar a ocorrência de expressivos agravos à saúde desse grupo, manifestando-se em desgastes que repercutem na sua vida e na qualidade da assistência à saúde prestada $(2,3,13-18,21)$. Entretanto, diante da problemática vivenciada no HE, de falta de pessoal, de entraves administrativos, de contingências históricas e sociais que repercutem na instituição pública, a realidade das cargas de trabalho parece ficar relegada a um segundo plano, consideradas menos imperiosas na dinâmica diária dos serviços.

A presente investigação oportunizou a maior compreensão das cargas de trabalho de materialidade externa do processo de trabalho de enfermagem do HE; os depoimentos denunciaram as dificuldades pelas quais passam os trabalhadores, sendo que medidas efetivas são necessárias objetivando minimizar tal realidade.

Cargas de materialidade externa existentes nos processos de trabalho têm trazido danos à saúde dos trabalhadores de enfermagem, constituindo-se em determinantes do seu processo saúde-doença. Essa problemática deve ser detidamente estudada no contexto social e particular de cada unidade laboral em que a atividade é desenvolvida, na busca da compreensão mais detalhada da realidade das equipes de trabalho.

Ações para aumentar o quantitativo de pessoal de enfermagem, adequar as condições do ambiente, inserção de novas tecnologias, maior disponibilidade de materiais e 
equipamentos, além de maior acompanhamento pelo Setor de Saúde Ocupacional são medidas fundamentais para a melhora das condições de saúde e trabalho dessa população, cujo desempenho é essencial na atividade produtiva da assistência à saúde, necessitando estar em boas condições físicas e psíquicas para realizar tal tarefa com competência e dignidade.

A falta de participação coletiva, sob a forma de atuação nos sindicatos e em entidades de classe e a ausência de esforços conjuntos para melhorar as condições de vida e trabalho do pessoal de enfermagem foram notórios no decorrer da investigação, o que evidencia a acanhada organização social dos trabalhadores, cujos efeitos, certamente, repercutem na situação de vida e saúde dos trabalhadores, assim como na qualidade dos serviços prestados no hospital.

Também, a necessidade de novos estudos na área, especialmente no que diz respeito às cargas de materialidade interna, uma vez que as cargas fisiológicas e as cargas psíquicas, da materialidade adquirida através da corporeidade humana, pela complexidade decorrente da sua invisibilidade externa ao corpo humano, das muitas variáveis particulares de cada indivíduo, gerando desgastes, requerem particular atenção.

São muitos os novos e desafiadores capítulos da temática empenhativa e comprometedora para os trabalhadores que é a saúde do trabalhador, que se renova a cada dia, em busca de intensificar o diálogo e o debate em torno das questões do trabalho, trazendo o trabalhador para esta discussão, possibilitando que ele entre em contato com a sua realidade, os seus desejos, as suas necessidades, a sua história.

\section{REFERÊNCIAS}

1. Laurell AC. La construcción teóricometodológica de la investigación sobre la salud de los trabajadores. In: Laurell AC, organizadora. Para la investigación sobre la salud de los trabajadores. Washington: Paltex; 1993. p. 13-35.

2. Laurell AC, Noriega M. Processo de produção e saúde: trabalho e desgaste operário. São Paulo: Hucitec; 1989.

3. Felli VEA, Tronchin MR. A qualidade de vida no trabalho e a saúde do trabalhador de enfermagem. En: Kurcgant $\mathrm{P}$ (coordenadora). Gerenciamento em enfermagem. $2 \mathrm{a}$ ed. Rio de Janeiro: Guanabara Koogan; 2010. cap. 8. p. 89-107.

4. Decreto No 3048 de 6 de maio de 1999. Aprova o Regulamento da Previdência Social, e dá outras providências. Diário Oficial da República Federativa do Brasil [Internet]; 20 nov 1970 [acesso 12 agosto 2009]. Disponível em: http:// www81.dataprev.gov.br/sislex/paginas/23/1999/3048.htm\#L1_T4.

5. Secco IAO. Acidentes e cargas de trabalho dos trabalhadores de enfermagem de um Hospital Universitário do Norte do Paraná. [Tese de Doutorado]. Ribeirão Preto: Escola de Enfermagem, Universidade de São Paulo; 2006. 291 p.

6. Bardin L. Análise de Conteúdo. Lisboa: Edições 70; 1977.

7. Minayo MC. Desafio do conhecimento. São Paulo: Hucitec; 2010.

8. Conselho Nacional de Saúde (BR). Resolução 196/96, de 10 de outubro de 1996. Diretrizes e normas regulamentadoras de pesquisa envolvendo seres humanos. Cad. Ética Pesqui. 1998; 1(1): 34-42.

9. Secco IAO, Robazzi MLCC. Acidentes de trabalho na equipe de enfermagem de um hospital de ensino do Paraná - Brasil. Cienc enferm. 2007 dez; 13(2): 65-78.

10. Lei $\mathrm{N}^{\circ} 6.174$ de 16 de novembro de 1970 (PR). Estabelece o regime Jurídico dos funcionários civis do Poder Executivo do Estado do Paraná. Diário Oficial do Estado do Paraná. [Internet]; 20 nov 1970 [acesso 8 agosto 2009]. Disponível em: http://www.portaldoservidor.pr.gov.br/ 
arquivos/File/estatutoservidor.pdf

11. Lei $\mathrm{N}^{\circ} 15.050$ de 12 de abril de 2006 (PR). Altera para Carreira Técnica Universitária a denominação da Carreira de Pessoal Técnico Administrativo das Instituições Estaduais de Ensino Superior do Estado do Paraná e adota outras providências. Diário Oficial do Estado do Paraná No 7205. [Internet]; 12 abr 2006 [acesso 8 agosto 2009]. Disponível em: http://www.unicentro.br/prorh/pccs/ LEI\%20N\%BA\%2015.050.pdf

12. Matos E, Pires D. Teorias administrativas e organização do trabalho: de Taylor aos dias atuais, influências no setor saúde e na enfermagem. Texto contexto-enferm. 2006; 15(3): 508-514.

13. Silva VEF, Kurcgant P, Queiroz VMQ. O desgaste do trabalhador de enfermagem: relação trabalho de enfermagem e saúde do trabalhador. Rev Bras Enferm. 1998; 51(4): 603-14.

14. Felli VEA. O trabalho gerencial em enfermagem. En: Kurcgant P (coordenadora). Gerenciamento em Enfermagem. 2a ed. Rio de Janeiro: Guanabara Koogan; 2010. cap. 1, p. 1-13.

15. Silva RM, Beck CLC, Magnago TSBS, Carmagnani MIS, Tavares JP, Prestes FC. Trabalho noturno e a repercussão na saúde dos enfermeiros. Esc. Anna Nery. 2011; 15(2): 270-276.

16. Santos EM, Araújo TM. Processo de trabalho e saúde dos trabalhadores no Hospital Universitário Professor Edgard Santos, HUPES. Rev Baiana Saúde Pública. 2003; jul-dez; 27(2): 155-68.

17. Ribeiro EJG, Shimizu HE. Acidentes de trabalho com trabalhadores de enfermagem. Rev Bras Enferm. 2007; 60(5): 53540.

18. Letelier SP, Valenzuela SS. Violencia: fenómeno relevante de estudio en campos clínicos intra-hospitalarios de enfermería. Cienc enferm. 2002; 8(2): 21-26.

19. Xelegati R, Robazzi MLCC, Marziale MHP, Haas VJ. Riscos ocupacionais químicos identificados por enfermeiros que trabalham em ambiente hospitalar. Rev Lat Am Enfermagem. 2006; 14(2): 214-9.

20. Castro MR, Farias SNP. A produção científica sobre riscos ocupacionais a que estão expostos os trabalhadores de enfermagem. Esc Anna Nery. 2008; 12(2): 364-69.

21. Robazzi MLCC, Mauro MYC, Dalri RCMB, Silva LA, Secco IAO, Pedrâo LJ. Exceso de trabajo y agravios mentales a los trabajadores de la salud. Rev Cuba Enferm. 2010; 26(1): 52-64. 